\title{
New Approaches to Understanding the Problem of a Choice Phenomenon
}

\author{
Nina A. Vasil'eva* \\ Irkutsk State Agricultural Academy \\ Pos. Molodezhny, Irkutsk region, 664038, Russia
}

Received 13.06.2016, received in revised form 08.07.2016, accepted 20.08.2016

\begin{abstract}
This article deals with different semantic interpretations of freedom in philosophy's history, such as necessity, (in) dependence, grace, fate, estrangement, responsibility, choice. We consider choice to be a semantic interpretation of content of the category of freedom and offer a new theoretical model of choice as a phenomenon.

In order to study the nature of choice more completely, today it is necessary to analyze the concept of choice from the positions of phenomenology and synergetics. Thus, this article describes some new approaches to understanding a choice phenomenon, namely, phenomenological and synergetic approaches, which allow marking out three stages in the mechanism of a choice's realization. They are immersing into chaos, being in chaos and going out of chaos.
\end{abstract}

Keywords: freedom, choice, theoretical model of choice, phenomenological approach, synergetic approach.

DOI: 10.17516/1997-1370-2016-9-10-2538-2546.

Research area: sociology.

\section{Introduction}

Freedom, being a great value, an ideal and one of the main characteristics of man, has been identified at different times with necessity, dependence (independence), grace, fate, estrangement, responsibility, will (choice). Hence, choice is a semantic interpretation of the content of the category of freedom.

Under the existing conditions of general destabilization of former social, economic, political, ideological structures and heterogeneity and the underdevelopment of new ones, each variant of society's development, especially in Russia, has no more than an alternative probabilistic character. In this regard, positive changes in the appreciation of the role of freedom and choice happen in society's consciousness. Choice takes an important place in man's and society's lives; it depends not only on inner motivation but also on outer determinants. People, living in unified and homogeneous societies, have much less opportunities to realize their choices than those, who live in open societies under the conditions of pluralism. Therefore, today one of the main tasks in the sphere of social philosophy may be determined as working out a new theoretical model of choice as a phenomenon.

(C) Siberian Federal University. All rights reserved

* Corresponding author E-mail address: vasileva.nina.66@mail.ru 


\section{The interpretations of a choice phenomenon in philosophy's history}

Ideas about new approaches to the problem's solution under today's conditions have formed not at once. While freedom is reasonable in classical philosophy, in postclassical philosophy theoretical aims at the solution of the problem of freedom (choice) are changed. In the middle of the $19^{\text {th }}$ century philosophical thoughts (Nietzsche, Dostoyevsky), as well as even psychology (Freud) at the beginning of the $20^{\text {th }}$ century came up to understanding that rationalistic ideas about man and freedom were unfounded. Russian religious philosophy regarded the problem of God's grace as self-determination of man. Existentialism introduced the so-called "freedom's idolatry". In some works of philosophers-existentialists of the $20^{\text {th }}$ century freedom appeared as a heavy burden, sometimes unbearable, causing emptiness, existential anxiety, escapism (E. Fromm). The barest necessity to search for freedom's action mechanisms, overcoming such states, arose sharply.

Beginning with the 1940s the problem of self-determination came into the field of vision of personality's philosophy and psychology (Frankl, Fromm, May and others), and only in the 1980s it was studied more seriously in the West (R. Harre, E. Dessy, R. Rayan, A. Bandura and J. Richlak). In the Soviet Science an interest in the problem of self-determination and choice appeared only in the 1960s, but it wasn't studied deeply. Some philosophical researches made an attempt to interpret the essence of choice (V.E. Davidovich, K.A. Novikov and others). Choice was examined from the positions of ethics, psychology, physiology, sociology, pedagogy and mathematical modeling.

The variety of applicable approaches to explain the essence of this conception emphasizes the complication of the problem. At the same time it should be noted that the facts themselves neither gave a complete integral idea of choice nor solved the problem of self-determination. Many authors, regarding choice as a phenomenon, conditioned by man's power over circumstances and his responsibility for accepted decisions, and giving a new definition of this conception, expressed in general outlines, didn't make it their aim to investigate the problem in detail. That's why the conception of choice was mot worked out insufficiently. But just at that period main approaches to the solution of the problem were outlined and they were developed subsequently in the 1980-90s.

\section{Theoretical model of a choice phenomenon \\ (New approaches to understanding the problem)}

In the post-Soviet philosophy and psychology some original works appeared, where various semantic models of choice were introduced (E.I. Kuz'mina, E.R. Kaliteevskaia, D.A. Leont'ev, G.A. Ball, V.A. Petrovskii, V. Borozdina, Iu. Kozeletskii, O.I. Larichev, G.N. Solntseva, F.E. Vasiliuk, N.F. Naumova and others), what made the idea about its nature more complete.

However, the essence of choice is supposed to have an outer determination, so the structure of this concept must be examined as a substantial determination, a concrete direction of subject object and subject - subject interaction.

The question about the structure of choice is also of great theoretical and practical importance. We begin to understand the essence of choice better, while extending our knowledge in the sphere of the choice structure. In philosophical literature the given question was explored insufficiently, but some investigators both Russian and foreign touched upon it indirectly (V. Vindelband, K.A. Novikov, E.F. Birn). However, doing justice to the supporters of a dialectical-materialistic 
conception, who admit objective existence and essence as well as phenomenon and examine them in a close correlation with each other, one cannot but mention that phenomenon is not identical with its essence. This misrepresentation is conditioned by the difference between essence and phenomenon, between essence and existence. Phenomenon is greater than essence as it includes not only the disclosure of essential connections, but also possible chance relationships, individual characteristics and others. In comparison with essence it is more mobile and dynamic.

Hence, in order to reveal the nature of choice more completely, today the conception of choice, according to the author, should be analyzed from the positions of phenomenology, where any distinction between phenomenon and essence becomes obliterated, and it is possible to find out the combination of essence and consciousness's stream, "self-supposition", "self-given", "selfmanifestation" of essence through phenomenon, as well from the positions of a synergetic approach.

\section{Phenomenological approach: semantic choice models}

Using a phenomenological method would allow discovering the complex inner nature of a category of choice. The organization of the given method involves investigating the proper intentional structure of consciousness with all essential components and in all directions. The analysis of the intentional structure of consciousness is realized in a reflexive way. So, phenomenology distinguishes a natural aim and a proper phenomenological one. In the world of daily thinking our life remains beyond any experience of the intentional direction of consciousness towards objects. Thanks to phenomenological reduction it is possible to ascend to the intentional structure of consciousness. Reduction allows becoming free from the natural aim of consciousness, which is directed towards cognizing outer objects. Reduction lets consciousness turn to investigating proper activities on objects' constructing.

The intentional analysis marks out an object, making definite sense, and on the other hand, changing phenomenon's ways, changing consciousness's modi. Husserl calls these mutually additional aspects of intentionality "noesis" and "noema", the essence and phenomenon. Noesis is a modus of intentional consciousness; noema is its subject sense, an objective correlate. Thus, phenomenological reduction allows describing noetic and noematic structures of consciousness. Husserl distinguished three types of reduction. They are psychological, ideatic and transcendental types.

Analyzing choice as a phenomenon, the author of the paper, supposes that the marked out models of ordinary, semantic and existential choices are neither more or less than the levels of phenomenological reduction. Is that really so?

Psychological reduction is directed towards the pure data of psychic experience. It discovers the field to pure psychic givenness. At that stage general essential qualities of this field are described by the experience of uninterrupted intentional explications and a subject remains still within the experience. Correlating with the essence of an ordinary choice, where it is to determine an optimal way of realizing the activity, directed towards achieving a result, we see that the subject's task is to determine which of alternatives conforms to the given criterion most and why it is more preferable than others.

We meet a more complicated variety of choice when any criteria for comparing alternatives are not given initially and a man has to construct them independently, for example, a choice of a profession or a spouse. As a matter of fact, the subject faces the task to determine the sense of each alternative, placing it in one's own vital world. It is a semantic choice. It conforms to 
essence of ideatic reduction, which leads to the necessity of essential discretion of phenomena; consciousness's subjects are analyzed from the point of view of their essential characteristics.

As Husserl wrote, this type of reduction is in the discretion of pure generalities, correlated with an infinite extent of freely thinkable possibilities as exceptionally possible facts, which are ordered by a norm of thinking as possible facts. These pure generalities are pure self-evidences in their essence. In order to discover the pure generalities of a phenomenological object, the method of "free variations in fantasy" is used, and thanks to it different sides of the phenomenological object vary absolutely arbitrarily, discovering the invariant, maintaining in all variants. It comes into being as a result of constant self-coincidences of variants. The semantic invariant that is general to all variants is the same for any possible variation "in general".

The method of "free variations in fantasy" concerns not only a phenomenological object, but also phenomenological subjectivity. As in the case with a phenomenological object, the ego describes the invariant of phenomenological subjectivity as an invariant of the "pure I" by varying possible variants consecutively. The method of free variation originally concerns only invariants of the ego proper, but when the question about understanding 'the other' and inter-subjectivity arises, then by analogy with my "ego", "the other" will have the same system of invariants.

Thus, the result of ideatic reduction can be any possible (conceivable) world with necessary attaching to being significant. In this connection Husserl explains that "after introducing extended reduction, the reduction to the phenomenological pure inter-subjectivity, the universal Apriori appears for subjects' communities, reduced to their inner phenomenological and pure unity" (Husserl, 1909, 124).
A much more complicated variant is also possible. The question is about important choices in some critical life situations when a subject is not given either criteria for comparing alternatives or alternatives themselves. The subject has to construct them without assistance together with possible future alternatives, which are choice's consequences and to make his choice on the basis of comparing possible future alternatives and possibilities of responsible realization of the chosen alternative. As in the fairy-tale, "if you go to the right, you will lose your horse, if you go to the left, you will be lost yourself". It is a personal (existential) choice, which concerns to transcendental reduction, whose aim is to clean consciousness radically and to find out the socalled primary sources of experience. Only in this way we come to the source of the intentional construction of the world.

The necessity of transcendental problems and, accordingly, of transition to transcendentally phenomenological reduction is explained by the being of subjectivity, "I". In this case the question is about subjectivity, constructing universal objectivity of the world. Since consciousness's subjectivity belongs to the real world, universal objectivity both in its reality and ideality appears as the definite world, provided with definite sense. As far as a transcendental purpose becomes free from any forms of conceivable and real worlds in motion of its own expansion, phenomenology creates its fundamental concepts from itself, including the phenomenon of choice.

Thus, analyzing a choice category as a phenomenon, it should be noted that models of ordinary, semantic and existential choices kept in it in a reduced form, whose essence becomes apparent in the process of subject's activity, throw light on the inner nature of the given phenomenon and equal electivity of its displays most completely, and also allow determining new semantic meanings of an ideal model of choice 
as a whole. Husserl, determining phenomenon as something "opening itself through itself", obliterates any distinction between phenomenon and object's or process's essence.

\section{Synergetics: the structure of choice}

Choice is a substantial definition. Therefore, in order to realize the most complex nature of the given phenomenon, we should turn to the synergetic approach as the most perspective direction in the system approach, that allows, according to the author, investigating social facts in their hidden semantic part and in the dynamics of the process of historical expansion, and also demonstrating clearly the strengthening of the role of personal activity in extreme situations, as well as the increase in the responsibility for accepted decisions, taking into account a complex of attendant determinants and maximum realization of the set goal.

According to Prigozhin, all systems include sub-systems, which constantly fluctuate. Sometimes separate fluctuation or their whole combination may be as a result of a positive (strengthening) reverse connection, so strong (not for nothing Lao-Tszy said that the weak conquers, the strong and that small reasons can cause great consequences), that the organization and structure of an open system, existed before, go to ruin. In this crucial moment of bifurcation that is choice, it is almost impossible to predict in what direction the system will develop; whether it will be unregulated or it will move up to a new, higher level of regulating and organizing. In the second case the system acquires a dissipated structure, which needs more energy for its maintenance than simpler structures replaced by it produce (Toffler, Prigozhin, Stengers, 1986, 30).

So, one of the key moments of synergetics is a possibility of spontaneous, "self-arbitrary", i.e. deterministic, but unpredictable origin and organization from disorder and chaos, a possibility of self-organization. In this sense synergetics and its conceptual apparatus (dissipated structures, a bifurcation point and others) are especially interesting for analyzing a choice category, its structure. The synergetic approach may be defined as investigating appropriate changes from the simple to the complex, from the complex to the most complex, in other words, cognizing complication processes of self-organization's ways and, accordingly, disorganization of open systems (Abramov, 2002, 15).

In a conceptual sense the basis of the problem solution of choice's action mechanisms is a synergetic paradigm, characterized by nonlinearity, irreversibility, instability, inequality. Together with the bifurcation mechanism these four categories form a new basic model of "selforganization processes, roughly fair to all three levels of organizing the material world - a lifeless substance, a live matter and a society" (Moiseev, 1998, p.72).

Thus, even if an integral logic of choice, i.e. its structure, uniting "outer" and "inner" logics, is possible, it is nonlineal logic. It should take into account the "human factor", which can be expressed namely in spontaneous and unpredictable actions, in its dependence on circumstances that seem inessential at first sight. It must explain choice as an action that is irreversible and crucial at the same time.

As applied to understanding the essence and structure of choice, synergetics is significant as it emphasizes the role of positive reverse connections between phenomena. Purposeful processes have been traditionally explained with the conception of a negative reverse connection. This conception is central in cybernetics and management theory, all automated mechanisms work on the principle of a reverse connection. Processes of such a type of connection have a purely causative character of regulating the 
system according to its parameters changing. The system itself does not have any "intentions", but as a result of purely mechanistic correlations of its parts it is capable of self-regulating. So, thanks to the conception of a negative reverse connection, behavior called "purposeful" and "expedient " acquires causative-deterministic explanation in the spirit of mechanistic rationalism (Viner,1983, 5-28).

Synergetic ideas allow separating mechanistic rationalism from rationalism, enriching rationalism by analyzing deterministic, but unpredictable processes like human actions and decisions in many cases. The positive reverse connection, intensifying the signal, got by the system at the entry, has been traditionally explained as destructive. Synergetics emphasizes a creative and constructive role of the given connection. As a matter of fact, that is how human behavior looks like in general, especially in crucial moments, namely, economic crises, techno-genus and ecological catastrophes, revolutions; the same are the situations, connected with a creative process in art and science. As A. Akhmatova said (Akhmatova, 1983, 90),

If you knew, from what a litter

Verses grow, dead to shame ...

Spontaneous displays are difficult to explain at first sight in actions of individuals, and in social behavior in general they are conditioned not by genetic potentialities, but by interaction of "man - social environment" system under unequal conditions. That is the nature of "crowd's psychology" and those are individuality's displays. "Nonlineal dynamics show that the basis of all these phenomena is the same mechanism" (Russian Academy of Sciences, 1996, 195).

Nonlinearity, that once meant the presence of some essentially different solutions of a mathematical equation, has assumed a fundamental sense nowadays, and, what is more, in our opinion, has become a methodological principle for analyzing the action mechanism of the category of choice.

Analyzing the action mechanism of choice we cannot help doing without the conception of bifurcation. Today this term means turning points of development, what emphasizes a choice situation, possibility of several versions of further events, and loss of stability of former states. The conception of bifurcation, born in mathematics, is used now by politicians, sociologists, psychologists, philosophers. The typical signs of bifurcation are sensitiveness to insufficient influences near the bifurcation point, instability of former states, and possibility of catastrophic leaps - final responses to infinitesimal influences.

Our time, thanks to E. Laslo, is often called the age of bifurcation, when the previous trajectory of development is losing stability, the danger of global catastrophes is increasing sharply and the choice situation is coming into being. According to E. Laslo, bifurcations in society's life can appear for such reasons as superficial perceptibility or wrong application of new technologies, arms race and political conflicts within the state, the ruin of a local socioeconomic order under the influence of crises becoming more frequent. In this case society only fragments and polarizes, having no time to structure itself again: a small part of people adapt to new conditions, while others are not able to change their status. Their disappointment creates the basis of reforms, growing into a revolution or coup d'etat. Chaos of social relationships comes in society, i.e. its conduct becomes unpredictable (Laslo, 1991, pp.18-19). The striking example of such development is the situation in Russia in the post-Soviet period.

Society's conduct in this situation will be unpredictable since at the bifurcation point unstable processes can go in any direction, and this "choice" is not determined, dependent on casual outer and inner factors. In point of fact, 
bifurcation is a mathematical way of "transition from quantitative changes to qualitative ones", what is one of the system's displays. "Quality's change under the influence of quantitative changes may happen only when an object has a systematic character" (Kuznetsov, 1996, 20). The ideological meaning of the bifurcation principle is in discovery of a new causation between the whole and the parts: the distinctive "mixing" of the whole and the parts, expressing a systematic character, in our case, of free will and free choice and operational genesis of their inner development.

At present it is hardly possible to deduce a strict "formula", disclosing the mechanism of choice action. Nevertheless, a contemporary set of instruments for mathematical modeling and computer experiments allows outlining the strategy and tactics of development of complex systems by drawing up scripts of synchronization of management and self-organizing systems, as well investigating the main moments of their development on the basis of standard models of "chaos-order" transition (catastrophes' theory, theory of self-criticism and others) in a formalistic form.

It is more difficult to describe such a delicate structure of choice, where the following three stages are marked out:

- Immersing into chaos (the origin of a choice situation).

- Being in chaos (the moment, when from a great number of alternatives the necessary one is being chosen, i.e. the moment of a proper choice).

- Going out of chaos (the moment, when the choice has been made, but is not realized yet, the ways to realize it are being planned) (selforganization).

Using such a method of approach, we inevitably come across the urgency of infinite hierarchical levels and ontological plans of formation by force of the presence of nonlineal reverse connections, i.e. factors of processes' self-influence that proceed on the micro-level to the structures' evolution on the macro-level, as well across infinite sensitiveness of unstable systems of outer influences.

Today a transition to chaos is a more studied stage, i.e. such a stage of system's evolution, when even insufficient fluctuations lead to disagreement of development within different substructures of a complex system; as a result, it runs the danger of disintegration. In other words, a choice situation is coming into being.

The next stage (being in chaos) is when dynamic chaos comes and carries wealth of possible structures, as well as impossibility of their absolute understanding; obviously they are bifurcation points themselves, where there is no other determinism, except deterministic strength of a human conscious choice.

But as soon as the choice is made, tough and mono-semantic lineal determination comes into force and acts till the next bifurcation point. Thereby necessity and chance form a dialectical unity, inter-conditioning each other. The dialectics are much greater than traditional rational schemes, where chance forfeits its meaning, dissolving in necessity, and plays an auxiliary role regarding it.

Nonlinearity of passing the bifurcation point brings together synergetic processes and choice's act not only by lack of tough and mono-semantic determination, but also by irreversibility. The result of each passing is the creation of a new reality and new reals, whose existence's possibility cannot be expected before the bifurcation point.

At last, the final stage - "chaos-order transition process" - is the origin of an order's parameter, choice among alternatives and potencies comes, and that means a "mystical" moment of the birth of a new structure. That, what is often called self-organization, is its completion, 
a simply observed chaos-order, a process of going out from its attraction field to a direction. But the fact is that at the chaos stage there is no developed direction, it has to be born, i.e. the realization of the made choice is still in prospect.

The typical example of such processes is consequences of definite political actions that resulted in the USSR's collapse and in the origin of the post-Soviet area, the countries of the Commonwealth of Independent States. All these chains can be regarded as consecutive changes of motivation, because each of new realities creates a new motivating mechanism, conditioning the origin of new directions and possibilities for new actions, opening new perspectives of development. That's why bifurcation and choice's irreversibility have a positive, constructive character. What is more, they determine not only uninterrupted dynamics and development of a motivating system of actions, but also dynamics of their explanations.

New realities force a subject to re-interpret the made choice, what makes a nonlineal objective act in a subjectively lineal way. After passing the bifurcation point that is choice, any action becomes irreversibly deterministic. So, after realizing accepted decisions, all alternatives, having equal possibilities before the bifurcation point and at it itself, are cut off. Thanks to such realizing man aspires to understand himself. In this sense motivation is a manifestation of personality's selfdetermination. Such an ability to rationalize actions gives man as a social being a great deal. It promotes gaining experience in rational actions. Man finds a possibility to influence on nonlineal bifurcation processes, even if not removing them totally, but essentially reducing the field of spontaneity in actions. It also gives an idea of responsibility for deeds.

\section{Conclusion}

Thus, analyzing the category of choice as a phenomenon, it should be noted that models of ordinary, semantic and existential choices kept in it in a reduced form, whose essence becomes apparent in the process of subject's activity, throw light on the inner nature of the given phenomenon and equal electivity of its displays most completely, and also allow determining new semantic meanings of an ideal model of choice as a whole.

As for the structure of choice, at present it is hardly possible to deduce a strict "formula", disclosing the mechanism of a choice action. Nevertheless we can mark out three stages:

- Immersing into chaos (the origin of a choice situation).

- Being in chaos (the moment, when from a great number of alternatives the necessary one is being chosen, i.e. the moment of a proper choice).

- Going out of chaos (the moment, when the choice has been made, but is not realized yet, its realization's ways are being planned) (selforganization).

This is the mechanism of a choice's realization as a phenomenon, given in general outlines, from the views of phenomenology and synergetics.

\section{References}

Abramov, Iu.F. (2002). Sinergo-gomeostaticheskii podkhod k probleme bezopasnogo ustoichivogo razvitiia regiona: Teoretiko-metodologicheskii ocherk [Synergetic-Homeostatic Approach to the Problem of Safe Stable Development of the Region: Theoretic-Methodological Essay]. Irkutsk, Irkutsk State University, $56 \mathrm{p}$.

Akhmatova, A. (1983). Beg vremeni [Time's Run]. Minsk, 255 p. 
Husserl, E. (1909). Logicheskie issledovaniia [Logic Researches], 1. Saint-Petersburg, 256 p.

Kuznetsov, V. I. (1996). Estestvoznanie [Natural Science]. Moscow, Agar, 383 p.

Laslo, E. (1991). Vek bifurkatsii [Bifurcation's Age]. Moscow, Mysl', 256 p.

Moiseev, N.N. (1998). Proshchanie s prostotoi [Parting with Simplicity]. Moscow, MNEPU, $480 \mathrm{p}$.

Russian Academy of Sciences (1996). Novoe v sinergetike. Zagadki mira neravnovesnykh struktur [Thr New in Synergetics. Riddles of the Unbalanced Structures' World]. Moscow, Nauka, 263 p.

Toffler, O., Prigozhin, I., Stengers, I. (1986). Poriadok iz Khaosa. Novyi dialog cheloveka s prirodoi [Order from Chaos: New Dialogue between Man and Nature]. Moscow, Progress, 432 p.

Viner, N. (1983). Kibernetika, ili upravlenie i sviaz'v zhivotnom i mashine [Cybernetics, or Management and Connection in Animal and Machine]. Moscow, Nauka, 343 p.

\title{
Новые подходы
}

\section{к пониманию проблемы \\ феномена выбора}

\author{
Н.А. Васильева \\ Иркутская государственная \\ сельскохозяйственная академия
}

Россия, 664038, Иркутская обл., пос. Молодежный

\begin{abstract}
Принято говорить о различных смысловых интерпретациях свободы в истории философии таких, как необходимость, зависимость, благодать, судьба, отчуждение, ответственность, выбор. Выбор рассматривается как семантическая интерпретачия содержания категории свободы; предлагается новая теоретическая модель выбора как феномена. Чтобы раскрыть природу выбора наиболее полно, необходимо проанализировать его с позиций феноменологии и синергетики. Таким образом, предложенные новые подходы к пониманию явления выбора, феноменологический и синергетический, позволяют выделять три стадии в механизме реализаиии выбора: погружение в хаос, бытие в хаосе и выход из хаоса.

Ключевые слова: свобода, выбор, теоретическая модель феномена выбора, феноменологический подход, синергетический подход.
\end{abstract}

Научная специальность: 22.00.00 - социологические науки. 